\title{
Alternativo versus convencional: uma análise da inserção de agricultores familiares periurbanos em circuitos de comercialização no município de São Luís/MA
}

\author{
Marcelo Sampaio Carneiro \\ Universidade Federal do Maranhão - São Luís - Maranhão - Brasil \\ ORCID: 0000-0002-7474-2694 \\ Camila Lago Braga \\ Universidade Federal do Rio Grande do Sul - Porto Alegre - Rio \\ Grande do Sul - Brasil \\ ORCID: 0000-0002-1211-9899
}

\begin{abstract}
Resumo
Este artigo analisa diferentes cadeias de comercialização (alternativas, convencionais ou institucionais) utilizadas por agricultores (as) familiares periurbanos, localizados na comunidade rural Cinturão Verde, no município de São Luís (MA), a fim de verificar em que medida se manifestam as dimensões da alternatividade e da convencionalização nessas cadeias, discutidas a partir de aspectos como o estabelecimento de relações de confiança, o papel desempenhado pelos intermediários, a definição dos preços e a questão dos critérios de qualidade dos produtos vendidos. Para atingir este objetivo, no ano de 2018, foram realizadas entrevistas com 10 agricultores, com a coordenadora de uma feira livre e gestores das políticas públicas de comercialização. Os resultados e conclusão revelam que as feiras livres, coordenadas em geral por atores externos a comunidade, se posicionam em uma busca por manter sua alternatividade através da tentativa de se diferenciar das cadeias convencionais e manter maior proximidade entre produtor e consumidor. Em contrapartida, as regras criadas nem sempre são aceitas pelos agricultores participantes, os quais acessam ao mesmo tempo as cadeias convencionais, com isso, torna-se difícil estabelecer um limite entre ambos os canais de comercialização acessados sejam estes mais convencionais ou mais alternativos, tendo em vista que os agricultores (as) do Cinturão Verde em seu processo de comercialização buscam primeiramente alcançar melhores rendimentos e garantir a reprodução social de suas famílias.
\end{abstract}

Palavras-chave: Agricultura Periurbana. Cadeias curtas. Alternativo. Convencional. 


\title{
Alternative versus conventional: an analysis of the insertion of peri-urban family farmers in marketing channels in the city of São Luís / MA
}

\begin{abstract}
This article analyze the different marketing chains (alternative, conventional or institutional) used by peri-urban family farmers, located in the rural Cinturão Verde community, municipality of São Luís (MA), in order to verify the extent to which the dimensions of alternativeness and conventionalization are manifested in these chains, discussed based on aspects such as the establishment of trust relationships, the role played by intermediaries, the definition of prices and the question of quality criteria of products sold. To achieve this objective, in the year of 2018, interviews were conducted with 10 farmers, with the coordinator of a fair and managers of public marketing policies. The results and conclusion show that fairs, generally coordinated by external players of the community, place themselves in a quest to sustain their alternativity through the attempt to differentiate themselves from conventional chains and keep greater proximity between producer and consumer. In contrast, the rules created are not always accepted by participating farmers, who access at the same time conventional chains, with that, it becomes difficult to establish a limit between both commercialization accessed channels, whether these are more conventional or more alternative, considering that the Cinturão Verde farmers in their marketing process seek first to achieve better yields and guarantee the social reproduction of their families.
\end{abstract}

Keywords: Peri-urban Agriculture. Short chains. Alternative. Conventional.

\section{Alternativa versus convencional: un análisis de la inclusión de los agricultores familiares periurbanos en los canales de comercialización en el municipio de São Luís / MA}

\section{Resumen}

Este artículo analiza diferentes cadenas de comercialización (alternativas, convencionales o institucionales) utilizadas por los agricultores familiares periurbanos, ubicados en la comunidad rural Cinturão Verde, en el municipio de São Luís (MA), para verificar en qué medida se manifiestan las dimensiones alternativa y la convencionalización en estas cadenas, discutidas en base a aspectos como el establecimiento de relaciones de confianza, el papel desempeñado por los intermediarios, la definición de precios y la cuestión de los criterios de calidad de los productos vendidos. Para lograr este objetivo, en 2018, se realizaron entrevistas con 10 agricultores, con el coordinador de una feria de productores y gerentes de políticas públicas de comercialización. Los resultados y la conclusión muestra que feries, coordinados por los actores externos en la comunidad en general, se colocan en una búsqueda para mantener su alternatividad al tratar de diferenciar de las cadenas convencionales y mantener una mayor proximidad entre productor y consumidor. Por otro lado, las reglas creadas no siempre son aceptadas por los agricultores participantes, quienes acceden a las cadenas convencionales al mismo tiempo, lo que dificulta establecer un límite entre ambos canales de comercialización a los que se accede, ya sean estos más convencionales o más alternativos. en vista del hecho de que los agricultores del Cinturón Verde en su proceso de comercialización buscan primero lograr mejores rendimientos y garantizar la reproducción social de sus familias.

Palabras clave: Agricultura periurbana. Cadenas cortas Alternativa Convencional 


\section{Introdução}

Este artigo analisa diferentes cadeias de comercialização (alternativas, convencionais ou institucionais) utilizadas por agricultores (as) familiares periurbanos, localizados na comunidade rural Cinturão Verde ${ }^{1}$, município de São Luís (MA), a fim de verificar em que medida se manifestam as dimensões da alternatividade e da convencionalização nessas cadeias, discutidas a partir de aspectos como o estabelecimento de relações de confiança, o papel desempenhado pelos intermediários, a definição dos preços e a questão dos critérios de qualidade dos produtos vendidos ${ }^{2}$.

Este debate é contextualizado a partir do papel que a Agricultura Urbana e Periurbana (AUP) vem assumindo, diante das especificidades que marcam o desenvolvimento de uma agricultura nas proximidades de áreas fortemente urbanizadas, sendo apresentada como um modelo alternativo de produção e consumo de alimentos em oposição ao modelo convencional. Assim, para além de um enquadramento espacial no sentido de superação da divisão entre urbano e rural, a AUP também conecta os locais de produção e de consumo, e integra os sistemas alimentares em todas as suas etapas de fornecimento (produção, colheita, distribuição, consumo etc.) e dimensões (sociais, econômicas, ambientais, nutricionais) (BLAY-PALMER; RENTING; DUBBELING, 2015).

Em contraposição ao modelo convencional, a insurgência de movimentos como a agricultura urbana, pode ser explicada pelas mudanças de percepção dos consumidores devido aos constantes "escândalos alimentares", colocando em cheque a qualidade dos alimentos advindos desse modelo dominante de produção e consumo (GOODMAN, 1999). Além disso, segundo Le Velly (2017), a natureza das relações em sistemas convencionais caracterizam-se por modos de produção racionalizados e estandardizados, com forte utilização de produtos químicos e nenhuma preocupação com o meio ambiente; cadeias dominadas por grandes empresas alimentícias e de distribuição; modos de consumo estão pouco preocupados e/ou conscientes das condições de produção e comercialização.

Nesse sentido, o debate sobre a insustentabilidade desses sistemas alimentares permitiu a emergência de estudos das Redes Agroalimentares Alternativas (RAA), termo utilizado para abranger as redes de produtores, consumidores e outros atores que incorporam alternativas ao modelo convencional de abastecimento alimentar (MURDOCH; MARSDEN; BANKS, 2000; RENTING; MARSDEN; BANKS, 2017). Para Goodman (2017), essa emergência provoca uma "virada" para a qualidade nas redes alimentares locais, direcionando as discussões para os locais de produção e de consumo nessas redes.

\footnotetext{
${ }^{1}$ O Cinturão Verde possui uma área de aproximadamente 382 hectares, que foi adquirida em 1998 com recursos do programa Cédula da Terra. Atualmente, vivem nesse povoado 87 famílias que possuem na atividade agrícola o seu principal meio de reprodução econômica, através da produção hortifrutigranjeira.

${ }^{2}$ Esta pesquisa foi realizada entre os meses de agosto a dezembro de 2018 , fruto da dissertação de mestrado intitulada "Circuitos de comercialização, mercados e estratégias de reprodução dos agricultores periurbanos da comunidade rural Cinturão Verde em São Luís (MA)" (BRAGA, 2019), pelo Programa de Pós-Graduação em Ciências Sociais, da Universidade Federal do Maranhão.
} 
Entre os estudos das RAAs, diversas abordagens são mobilizadas para discutir as experiências que envolvem uma relação direta entre produtor e consumidor, cujas características se diferenciam a depender das perspectivas teóricas adotadas. No caso das Cadeias Curtas de Abastecimento Alimentar (CCAA), desenvolvidas por Marsden, Banks e Bristow (2000), são apresentadas como expressões de tentativas (ou lutas) de produtores e consumidores para igualar novos tipos de oferta e demanda; busca pela vinculação do preço com critérios de qualidade; ênfase no relacionamento entre o produtor e consumidor, bem como, o papel desse relacionamento na construção de valor e significado. São exemplos de CCAAs, as feiras do produtor, entrega de cestas de alimentos, venda na propriedade, venda institucional para a alimentação escolar, bem como, outras formas de venda direta (DALROT et al., 2016).

De forma semelhante, a noção de "circuito de proximidade" discutida por Aubry e Chiffoleau (2009) reforça a ideia de proximidade geográfica, a ligação entre produtor e consumidor, desenvolvimento dos mercados locais, com redução ou eliminação dos intermediários nas relações entre produtores e consumidores. Como explicam Schneider e Gazolla (2017, p. 13):

Seja qual for a denominação, a maioria das iniciativas visam criar alternativas à lógica e às modalidades organizativas do sistema agroalimentar dominante, buscando o encurtamento das distâncias (físicas, sociais, culturais, econômicas) entre o ‘mundo' da produção e do consumo.

A partir dessa discussão teórica, procuramos analisar as estratégias de comercialização desenvolvidas pelos (as) agricultores (as) do Cinturão Verde, com o objetivo de verificar como eles (as) acionam diferentes tipos de circuitos de comercialização e quais as questões mais importantes para a mobilização desses circuitos.

Para a análise das cadeias de comercialização acessados pelos agricultores (as) periurbanos do Cinturão Verde, consideramos a tipologia desenvolvida por Wilkinson (2008), o qual identifica pelo menos quatro formas tradicionais de acesso aos mercados: "acesso direto, sobretudo no caso do mercado local (informal); intermediação via atravessador; integração com a agroindústria ${ }^{3}$; e compras por parte do poder público". Apoiados nessa tipologia, classificamos esses mercados como alternativos (relativo ao acesso direto), convencionais (presença de atravessadores) e institucionais (políticas de compras públicas).

Como procedimentos metodológicos, a partir de um roteiro semiestruturado, realizamos 10 entrevistas com agricultores do Cinturão Verde de forma a verificar o acesso aos diferentes canais de comercialização. Foram realizadas conversas com o presidente da associação do Cinturão Verde, com a coordenadora da Feira da Agronomia, e com quatro gestores das respectivas

\footnotetext{
${ }^{3}$ Não estão incluídas na tipologia discutida na pesquisa, por não terem sido encontrados formas de comercialização com integração a agroindústria.
} 
secretarias estatuais e municipais ${ }^{4}$ que operacionalizam as políticas públicas de comercialização, caso do Programa de Aquisição de Alimentos (PAA), Programa de Compras da Agricultura Familiar (PROCAF) e Programa Nacional de Alimentação Escolar (PNAE).

O artigo está organizado em cinco seções a contar da presente introdução. A segunda seção constitui o marco teórico e conceitual, no qual são apresentadas definições centrais que darão suporte à análise, onde discutimos a abordagem das Cadeias Curtas de Abastecimento Alimentar (CCAA) e sua promessa de alternatividade frente o modelo convencional de abastecimento alimentar. $\mathrm{Na}$ seção três, apresentamos uma breve caracterização da agricultura urbana em São Luís (BRAGA; CARNEIRO, 2019), de forma a contextualizar a experiência dos agricultores do Cinturão Verde. Na seção subsequente, analisamos os tipos de comercialização e circuitos acessados pelos agricultores do Cinturão Verde, a partir de quatro dimensões das CCAAs, a saber: a relações de confiança, redução do número de intermediários, preços justos, e qualidade. Na conclusão retomamos o debate acerca da dicotomia alternativo versus convencional, procurando verificar de que forma a experiência analisada se insere nessa discussão.

\section{Redes Agroalimentares Alternativas e Convencionais: perspectiva teórica e conceitual}

A gênese das pesquisas voltadas as Redes Agroalimentares Alternativas (RAA) datam dos anos 1990, quando surge uma serie de estudos sobre as novas configurações do rural, passando a serem identificadas experiências que parecem divergir do modelo dominante que a "modernização agrícola" propusera (SAGE, 2013). Neste sentido, experiências como as da venda direta ao consumidor, do agroturismo e da comercialização de produtos identificados com signos de qualidade diferenciada (a agricultura orgânica ou as denominações de origem controlada), apresentam-se como alternativas ao sistema convencional.

Assim, essas experiências em RAAs, para alguns autores (PLOEG et al., 2000), surgem como componentes de um "novo paradigma de desenvolvimento rural", descritos a partir de transformações na forma de pensar o trabalho dos agricultores e o lugar da agricultura na sociedade. Para Marsden e Renting (2017), apesar de resistências ao desenvolvimento do paradigma rural-urbano sustentável, é possível constituição de uma rede mais diversa e mais densa de cadeias curtas de abastecimento, principalmente através dos mecanismos de governança criados pela sociedade civil, demandando um engajamento tanto de produtores rurais como de consumidores urbanos.

Ao mesmo tempo em que se tem um debate a respeito da alternatividade dessas redes, também surgiram pesquisas questionando a capacidade desses modelos alternativos responderem as crises do sistema convencional, caso este da "convencionalização" da agricultura orgânica, como defende Julie Guthman (2002), ao apontar para a presença crescente dos modos de produção capitalista e

\footnotetext{
4 Uma pessoa da Secretaria de Agricultura, Pecuária e Pesca (SAGRIMA), duas da Secretaria de Agricultura Familiar (SAF) e um coordenador da Secretaria Municipal de Pesca e Abastecimento (SEMAPA) de São Luís.
} 
industriais em detrimento dos princípios agroecológicos. Poméon et al. (2017) explicam que o processo de convencionalização surge a partir do enfraquecimento do escopo crítico da agricultura orgânica, sobretudo em decorrência do processo de institucionalização através de um padrão de mercado certificado, em contrapartida, se presencia um movimento contemporâneo para reativar a dimensão crítica e alternativa do orgânico por meio do renascimento da certificação participativa e da multiplicação de padrões privados com o objetivo de exceder o padrão público. Neste sentido, Angela Tregear (2011) se propõe a discutir a partir de uma revisão crítica, quais os limites das pesquisas desenvolvidas nos últimos anos a respeito das RAAs. Inicialmente, aponta para quatro características dessas redes segundo estudos realizados. A primeira característica reivindicada é a sua ancoragem em um local específico, como por exemplo, através das cadeias curtas (MARSDEN; BANKS; BRISTOW, 2000) com a produção, processamento, varejo e consumo ocorrendo dentro de uma determinada área geográfica, ou quando, mesmo com certa distância geográfica entre o local de produção e de consumo, o produto comunica sua origem através de informações presentes nas embalagens, também chamado de "cadeias estendidas" (RENTING; MARSDEN; BANKS, 2017). A segunda característica se refere a sua orientação para a viabilidade econômica para os atores envolvidos. A terceira reforça sua base de sustentabilidade ecológica e, por último, reivindica características de justiça social através de uma reconfiguração das relações entre produtores e consumidores.

A partir disso, a autora apresenta algumas críticas aos estudos realizados em RAAs, tais como: a) uso inconsistente do termo, pois, é apresentado de acordo com o que ele não é, dessa forma, as bases para definir o que é o "alternativo" variam muito, acarretando em uma tendência a coloca-lo sempre em oposição ao convencional, torna-se problemático quando usado como um termo universal para um conjunto heterogêneo de sistemas alimentares; b) a confluência das características estruturais dos sistemas alimentares com os resultados desejados e / ou os comportamentos dos atores, levando a uma mistura dos fenômenos estudados, já que confunde características estruturais e espaciais; c) reconhecimento insuficiente dos problemas do mercado de negociação; d) falta de uma perspectiva do consumidor.

Considerando esses limites apresentados, Fonte (2010) acrescenta que essa dicotomia entre convencional e alternativo reforçada em muitos estudos das RAAs, já foi superada, pois o "convencional e alternativo operam em espaços econômicos contíguos, interseccionando e sobrepondo-se um ao outro" (p. 1). Sonnino e Marsden (2017) apontam para um hibridismo entre o que se denomina como "alternativo" e o "convencional", demonstrado através das práticas de agricultores e consumidores que atuam em ambos os sistemas, tornando difícil delimitar as fronteiras entre ambos. Em contrapartida, Le Velly (2017), ao estudar os circuitos locais de comercialização, afirma que tais abordagens remetem a uma ideia de hibridação entre sistemas convencionais e alternativos, desta forma, sugere analisar as compras locais como espaços híbridos, não no sentido de um grande compartilhamento entre circuitos longos e curtos, mas a partir das atividades de 
regulação ${ }^{5}$ que, por sua vez, podem depender de relações de oposição, mas também das relações de coabitação e relações mais simbióticas, permitindo haver um continuum que varia de nenhum compromisso, para uma cooperação aprofundada, passando por uma coabitação não conflituosa. Assim, o que é híbrido não são os sistemas alimentares, mas as atividades de regulação que permeiam os sistemas alternativos e convencionais.

Neste sentido, Le Velly (2017) propõe refletir acerca da "alternatividade" desses sistemas, não porque suas práticas estão realmente rompendo com os sistemas convencionais, mas porque seus projetos são marcados pelo que ele denomina de "promessa da diferença", o qual define como "a promessa de outra modalidade de organização da produção, das trocas e/ou do consumo alimentar, e a promessa de benefícios associados" (p.24). É através dessa promessa que os atores definem as razões pelas quais é necessário agir e, a partir disso, manifesta a capacidade de projetar e mover-se em favor da criação de alternativas.

A partir desse debate, citamos especificamente as Cadeias Curtas de Abastecimento Alimentar (CCAA), considerando a agricultura urbana e periurbana como espaços de emergência crescente das RAAs através do aumento da demanda de consumidores urbanos por alimentos mais naturais, frescos e orgânicos (SCHNEIDER; GAZOLLA, 2017).

Portanto, para Marsden; Banks e Bristow (2000), as CCAA são caracterizadas a partir da capacidade de redefinir a relação entre o produtor e o consumidor, privilegiando a origem do produto alimentar; socializar e localizar o produto com o propósito de gerar vínculo com a propriedade; tentativas de combinar novos tipos de oferta e demanda; a busca pela construção da qualidade; e um destaque para as relações entre consumidor e produtor, cheia de valores e significados, ultrapassando os limites das trocas econômicas de um produto em si. Essas características aludem a uma conexão existente entre consumidor e produtor de alimentos, permitindo que o consumidor associe-se com o lugar de produção e, potencialmente, os valores das pessoas envolvidas e os métodos de produção empregados.

Com base nessa definição, os mesmos autores identificaram três tipos de relações em CCAA, a saber: relação "face a face", privilegiando a interação pessoal e relações de confiança; a "proximidade espacial" cujos alimentos são produzidos e distribuídos na sua região de origem e o consumidor tem conhecimento da natureza "local" desse produto; por fim, "a extensão espacial", no qual valor e significado envolvidos no processo de produção e relativos ao local em que foi produzido são traduzidos ao consumidor, a partir de informações dispostas nas embalagens do produto, como por exemplo, através do processo de garantia da qualidade (certificação). Assim, os autores apresentam como elementos importantes, nesse contexto, os parâmetros organizativos (produtores e consumidores), fatores culturais transmitidos pela confiança e a valorização do mercado local.

\footnotetext{
${ }^{5}$ Segundo Le Velly (2017, p. 26) são "atividades que ajudam a construir o coletivo e regular relações dentro dele", as quais podem ser "regras escritas, dispositivos técnicos, discursos, relações estáveis, rotinas e convenções".
} 
Le Velly (2017) acrescenta que os estudos sobre "Circuitos Curtos de Comercialização" envolvem um ou mais dos seguintes elementos: a ideia de proximidade do local de produção e consumo, a presença de consumidores reflexivos (consum'atores) e a obtenção de preços mais justos ao produtor tornando-os responsáveis por transformar a realidade dos que produzem o alimento.

\subsection{Dimensões da Alternatividade das Cadeias Curtas}

Chamamos atenção para algumas dimensões das cadeias curtas presentes na literatura e que embasaram nossa pesquisa empírica, isto é, a proximidade entre produtores e consumidores; a redução ou eliminação do intermediário; preços justos; e qualidade dos alimentos. Estas perspectivas são mobilizadas, sobretudo, a partir das teorias desenvolvidas pela Sociologia Econômica, a qual entende os mercados como construções sociais (POLANYI, 2000; GRANOVETTER, 2007; STEINER, 2006).

Segundo Sonnino e Marsden (2017, p. 105), as redes alternativas, que remetem a características como "qualidade", "transparência" e "localidade", tem sinalizado um afastamento "do setor de alimentação industrializado e convencional em direção a um regime alimentar e agrícola relocalizado". Da mesma forma, busca-se romper com as cadeias industriais a fim de reconstruir a relação entre produtor e consumidor, pois conforme explica Marsden, Banks e Bristow (2000, p. 425), as CCAAs se posicionam a fim de "redefinir a relação entre produtorconsumidor, dando sinais claros quanto a origem do produto alimentar", e acrescentam que sua capacidade de construir valor e significado potencializam a demanda por preços melhores aos produtores. Portanto, a reconexão entre produtores e consumidores está presente nos mercados de proximidades, que, de acordo com Sabourin (2013, p. 8), caracterizam-se pela "complementaridade entre os atores, a intercomunicação, a sociabilidade e a preocupação com a subsistência". Complementa dizendo que a proximidade remete ao conceito de "reciprocidade", pois no processo de comercialização de produtos agropecuários, os agricultores familiares e suas organizações apresentam vários tipos de interfaces, que permitem uma coabitação entre a reciprocidade e a troca.

Esta ideia reforça a responsabilidade do consumidor transformar-se em um consum'ator (LE VELLY, 2017), justificada pelo aumento na procura por alimentos com características locais, artesanais e técnicas diferenciadas de produção, despertando nos consumidores a contribuição econômica e social que engloba a compra de produtos da agricultura familiar (DILL et al., 2014). Nesta mesma perspectiva, Cordeiro (2014) afirma que se trata de um espaço que transcende a esfera das trocas comerciais, oportunizando experiências de intercâmbio cultural e aprendizagem coletiva na interface entre os universos urbano e rural. O mesmo

\footnotetext{
${ }^{6}$ Para os autores, "relocalizado" no sentido de trazer de volta para o local, em contraposição à tendência de globalização/universalização da produção e consumo de alimentos (SONNINO; MARSDEN, 2017).
} 
ocorre em cadeias curtas controladas socialmente por organizações de produtores ou pelas cooperativas de consumidores (SABOURIN, 2013).

Em um contexto de reconexão entre produtor e consumidor se insere também o debate sobre "relocalização", quando, para alguns autores, o alternativo é identificado como o local, e o convencional como o global. Assim, a relocalização das fontes alimentares é apresentada como estratégia de autoproteção, em que o local torna-se um espaço autônomo de resistência para produção de alimentos alternativos, vinculada as práticas locais de cultivo, natureza, paisagens e recursos rurais, enquanto que o sistema convencional é marcado pela deslocalização dos sistemas alimentares, através de processos de produção padronizados e especializados, referindo-se não somente ao distanciamento geográfico entre o produtor e o consumidor, mas a perdas das características originais dos alimentos e seu vínculo sociocultural (PREISS; MARQUES, 2015). Contudo, Brunori e Galli (2016) ao estudarem a sustentabilidade das cadeias alimentares locais e globais, apontam para o perigo em se usar critérios de distância físicas para definir o que é local e o que é global, já que o convencional também pode ser local, e vice versa. Sonnino e Marsden (2017, p. 108) afirmam que "alguns estudos de caso demonstraram que, por vezes, embora se possam estabelecer distinções abstratas entre os sistemas alimentares alternativo e convencional, não há uma fronteira precisa entre eles".

Uma segunda dimensão da alternatividade presente nas CCAAs refere-se à presença de no máximo um intermediário no processo de comercialização, portanto, dentre suas características está o estabelecimento de uma relação mais direta possível com os consumidores com o propósito de evitar que os intermediários comerciais lucrem à custa dos produtores, buscando assim, um rompimento com a lógica convencional da troca mercantil (LE VELLY, 2017).

Contudo, algumas questões sobre o papel dos intermediários merecem atenção, pois permite uma leitura menos maniqueísta de sua presença junto aos produtores e do papel desempenhado, que, em algumas situações, pode ser benéfico ao produtor.

Esse é o caso, por exemplo, do estudo apresentado por Craviotti (2017), sobre a participação de agricultores familiares em um mercado de leite na Argentina, destacando o papel positivo desempenhado pelos intermediários, uma vez que além de participar do processo de comercialização eles também oferecem serviços- como insumos, alimentos, transporte etc. -, que são necessários para a reprodução dos agricultores familiares. Portanto, a figura do intermediário varia segundo a localização e as condições da infraestrutura de acesso aos mercados.

Em terceiro lugar, há o debate acerca da questão dos preços justos, haja vista que uma das promessas das RAAs refere-se a possibilidade do fortalecimento socioeconômico de produtores e consumidores, que foram excluídos do sistema alimentar dominante, os quais funcionam com pressões por preços competitivos e economias de escala impostas sobre elas pelo sistema industrial (ALLEN et al., 2003). Neste sentido, Belletti e Marescotti (2017) apresentam os preços definidos nos CCAAs a partir de uma lógica de valor total, ligado não somente a valor de uso imediato do produto, mas também a seu valor social, haja vista que muitos destes não são diretamente quantificáveis em termos monetários, à exemplo das transações decorrente de mecanismos de solidariedade entre consumidores e produtores e sustentabilidade (econômica, social e ambiental). 
A quarta dimensão diz respeito à qualidade dos alimentos, reivindicada em um contexto onde os consumidores cada vez mais reflexivos demandam produtos com base em aspectos qualitativos, colocando o preço dos produtos em segundo plano (SCHNEIDER; GAZOLLA, 2017). Niederle e Almeida (2013) acrescentam que houve mudança nos últimos anos no âmbito do consumo através da crescente expectativa social pela produção que preserva o meio ambiente, promove equidade social, valoriza a artesanalidade da produção, as tradições envolvidas, dando importância a sua origem 7 . Neste sentido, como aponta Marsden (1998, pag. 107), os "mercados de alimentos estão se tornando mais diferenciados com base em uma série de critérios socialmente construídos sobre qualidade dos alimentos", resultando em novos mercados que se diferenciam dos sistemas convencionais.

Sendo assim, destaca-se que existem outras dimensões privilegiadas nas pesquisas sobre redes alimentares alternativas, mas para esse estudo foram trabalhadas aquelas que consideramos mais facilmente identificadas nos discursos das pessoas entrevistadas. Além disso, essa discussão permite compreender as dinâmicas existentes entre os mercados acessados por agricultores periurbanos, problematizando os conceitos que caracterizam as cadeias curtas.

\section{0 polo agrícola do Cinturão Verde e a agricultura periurbana de São Luís.}

O Cinturão Verde é um povoado localizado no município de São Luís (Mapa 1), principal aglomeração urbana do estado do Maranhão, que possui uma população estimada de 1.101 .884 habitantes. Apesar de predominantemente urbana, São Luís possui uma importante zona rural, de onde se origina parcela relevante dos alimentos consumidos na capital do estado. De acordo com Braga e Carneiro (2019), atualmente existem 51 polos de produção agrícola no município, dentre os quais o do Cinturão Verde.

\footnotetext{
7 Renting, Marsden e Banks (2017) apontam para duas categorias definidoras de qualidade nos CCAAs, são elas: qualidade atribuída ao produto e ao lugar de produção ou produtor, o qual remete ao lugar de produção (condições naturais, tradições culturais) ou processo de produção (artesanal, tradicional, etc.); e qualidade definida em termos de produção alimentar e consumo relacionado a bioprocessos, voltados à multifuncionalidade da agricultura.
} 
Mapa 1 - Mapa de localização geográfica da MRH da Aglomeração Urbana de São Luís (MA)

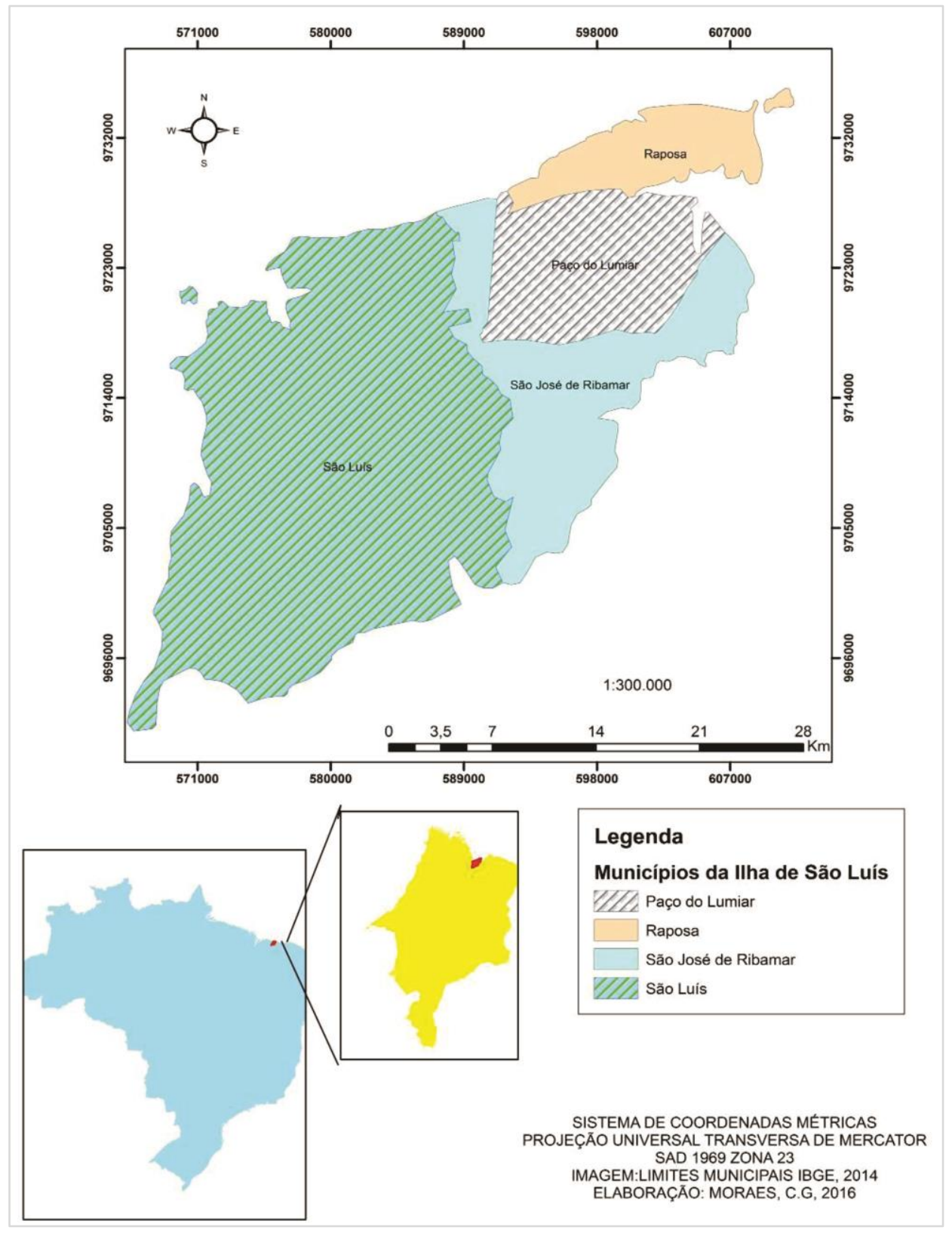

Fonte: GOMES (2016)

A forte presença desses polos agrícolas - que perfazem 97 quando consideramos todos os municípios que integram a llha de São Luís ${ }^{8}$ - faz com que a agricultura familiar tenha um papel de destaque no abastecimento de feiras e mercados da cidade. Nesse sentido, vale destacar que, de acordo com o último Censo Agropecuário, a agricultura familiar da Aglomeração Urbana de São Luis possuía 2.542 estabelecimentos ( $86,31 \%$ do total), ocupava 2.616 hectares (52,85\% do

\footnotetext{
${ }^{8}$ Inclui os municípios de São José de Ribamar, Paço do Lumiar e Raposa, que, em conjunto com São Luís, integram a MRH da Aglomeração Urbana de São Luís.
} 
total) e respondeu por cerca de $65 \%$ do valor total da produção (BRAGA; CARNEIRO, 2019).

\subsection{As feiras e mercados acessados pelos produtores do Cinturão Verde.}

A venda de produtos hortifrutigranjeiros em São Luís/MA é realizada por diversos tipos de agentes e instituições, que inclui Centrais de Abastecimentos (CEASA e mercado do João Paulo), mercados municipais organizados ou supervisionados pela Prefeitura (mercados públicos localizados em vários bairros da cidade), feiras livres e, em período mais recente, feiras de caráter agroecológico, organizadas por grupos da sociedade civil em parceira ou não com agentes do Estado. No caso dos agricultores (as) do Cinturão Verde, são acessadas algumas feiras livres; feiras de bairros, com predominância de comerciantes; centrais de abastecimento, com destaque para o Mercado do João Paulo; somam-se ainda os mercados institucionais (PAA, PNAE e PROCAF).

Das feiras livres acessadas por agricultores do Cinturão Verde, citamos a Feirinha da Agerp, Feirinha da Agronomia, Feira da SAF, Feira São Luís Rural do Angelim e Feira da Vila Sarney.

A feirinha da Agerp teve início em 2006 no bairro do João Paulo, localizado no município de São Luís. Atualmente, é gerida pela Agência Estadual de Pesquisa Agropecuária e Extensão Rural do Maranhão (AGERP) e acontece no estacionamento do referido órgão, funcionando todos os sábados a partir das seis horas da manhã e abrange produtores rurais da ilha de São Luís, um total de 20 agricultores familiares, entre eles, quatro famílias do Cinturão Verde.

Em 22 de março de 2016, por iniciativa do Departamento de Economia Rural da Universidade Estadual do Maranhão (UEMA), foi criada a Feirinha da Agronomia que acontece todas as terças-feiras, das 13 às 18 horas, em frente ao prédio do curso de Engenharia Agronômica. Atualmente, existem 10 produtores que participam semanalmente, sendo que uma das regras para participar é a proibição da comercialização de produtos comprados em mercados convencionais. Sendo assim, somente é vendido o que é produzido por agricultores familiares locais.

A Feira São Luís Rural do Angelim é realizada todos os sábados, no bairro do Angelim, no município de São Luís, gerida pela Secretaria de Agricultura, Pesca e Abastecimento (SEMAPA). A Feirinha da SAF é uma iniciativa da Secretaria de Agricultura Familiar (SAF) e é realizada no espaço interno da sede da Secretaria.

Atualmente, por meio de uma parceria entre a Cooperativa de Agricultores Familiares do Cinturão Verde (COAFACIV) e a União dos Moradores da Vila Sarney, foi criada a Feira da Vila Sarney, iniciada em setembro de 2018, acessada por seis agricultores do Cinturão Verde e localizada no bairro de mesmo nome, a $7 \mathrm{~km}$ do Cinturão Verde.

Há também os casos de venda direta, na qual os consumidores deslocam-se ao Cinturão Verde para comprar diretamente dos produtores. Esse tipo de comercialização ocorre principalmente para compra de farinha d'água e de frango caipira, porém é realizada de forma esporádica.

A feira da Nova República, localizada no bairro da Vila Nova República, fica a $9 \mathrm{~km}$ do Cinturão Verde. Anteriormente, era ocupada somente por feirantes comerciantes, atualmente é utilizada por quatro agricultores do Cinturão Verde, 
após a iniciativa de um agricultor da comunidade que, devido à dificuldade em comercializar o excedente da sua produção, tendo em vista o atraso dos Programas de compras públicas, passou a levá-los para essa feira que ocorre todos os dias.

A venda indireta é realizada principalmente com agentes que atuam na feira do João Paulo, que é um dos centros distribuidores de São Luís - tal como as centrais de abastecimento - CEASA. Geralmente, os produtos comercializados no João Paulo são intermediados por um ou mais atravessadores, ou são vendidos aos feirantes comerciantes. Ademais, outros atravessadores, duas vezes na semana, vão ao Cinturão Verde para comprar frangos a fim de redistribuir a restaurantes e boxes de venda nas feiras da cidade, que podem ser próprios ou de terceiros. Acrescentamos, que outros produtores também tornam-se intermediários quando compram parte da produção local para diversificar os produtos que são vendidos nas feiras ou mesmo no João Paulo.

Por último, existem os Mercados Institucionais, representados pelo PAA, PNAE e PROCAF. Anteriormente, o PAA era operacionalizado pela Companhia Nacional de Abastecimento (CONAB) nesta comunidade, mas atualmente, existem duas instituições que possuem chamadas públicas individuais através da modalidade denominada Compras institucionais, as quais foram acessadas pelos agricultores cadastrados pela Cooperativa do Cinturão Verde, a saber: o Exército e o Instituto Federal do Maranhão (IFMA). O PNAE é acessado por meio de chamadas públicas para entrega de alimentos às escolas comunitárias da cidade ${ }^{9}$. O PROCAF é financiado pelo Fundo Maranhense de Combate à Pobreza (FUMACOP). O edital de 2018 atendeu os agricultores familiares apenas nos meses de outubro e novembro, somando um total de $R \$ 4.500,00$, dividido em duas vezes.

\section{Dimensões da alternatividade: o caso dos agricultores periurbanos do Cinturão Verde}

Com base na categorização apresentada por Wilkinson (2008), enquadramos os circuitos de comercialização acessados pelos agricultores do Cinturão Verde como: "alternativos" em cadeias curtas; "convencionais" em cadeias curtas; "convencionais" em cadeias longas; e mercados institucionais (Quadro 1).

Quadro 1 - Categorização dos Circuitos de Comercialização utilizados pelos agricultores periurbanos de São Luís/MA

\begin{tabular}{|l|l|c|}
\hline \multicolumn{1}{|c|}{ Mercados } & \multicolumn{1}{|c|}{ Cadeias curtas } & Cadeias longas \\
\hline Alternativos & $\begin{array}{l}\text { Feira da Agricultura Familiar da AGERP, } \\
\text { Feirinha da Agronomia, Feira São Luís } \\
\text { Rural do Angelim, Feirinha da SAF, } \\
\text { Feira livre da Vila Sarney. }\end{array}$ & \\
\hline Convencionais & Feira da Nova República & Mercado do João Paulo \\
\hline Institucionais & PAA, PNAE e PROCAF & ----- \\
\hline
\end{tabular}

Fonte: Elaborada pelos autores

\footnotetext{
${ }^{9}$ No ano de 2018, não houve edital do PNAE lançado, mas entregaram alimentos em escolas nos meses de setembro e outubro, com pagamentos referentes às contas do ano passado.
} 
O "alternativo" é apresentado como venda direta na propriedade, bem como, em "feiras livres", mas também encontramos esta forma de comercialização em espaços com predominância de feirantes comerciantes, que, para os agricultores participantes tratam-se de mercados "convencionais em cadeias curtas".

O "convencional em cadeias longas" é destacado pela venda indireta realizada em centrais de abastecimentos (mercado do João Paulo) e ao atravessador que vai até a propriedade. Por fim, a comercialização nos Mercados Institucionais, através do PNAE, PAA e PROCAF, representam um novo mercado definido por instituições diferenciadas das convencionais a qual comunica a origem do produto e novos critérios de qualidade (TRICHES, 2015), podendo ser enquadradas como cadeias curtas $^{10}$.

A fim de diferenciar os circuitos de comercialização, procuramos analisar as motivações que levaram os agricultores do Cinturão Verde a acessá-los, considerando quatro aspectos: a) relações de confiança; b) a redução do intermediário; c) preços justos; d) qualidade dos alimentos.

\subsection{Relações de confiança}

$\mathrm{Na}$ comunidade Cinturão Verde, dos sete mercados físicos acessados, somente o Mercado do João Paulo não se caracteriza como venda direta. Portanto, as seis feiras representam um importante canal de comercialização, possibilitando essa proximidade com o consumidor, caracterizada pela relação face a face (MARSDEN; BANKS; BRISTOW, 2000).

Observamos nos alternativos algumas variações a respeito das relações sociais estabelecidas e do público atendido. Na Feira São Luís Rural do Angelim, dois agricultores entrevistados relataram a presença de redes sociais que se formam para além do espaço de comercialização, com recorrência de visitas de consumidores em suas propriedades, principalmente de gestores de escolas atendidas pelo PNAE, que frequentam regularmente a feira. Na feirinha da agronomia, existem consumidores que, em sua maioria, são estudantes e professores da UEMA e, em número menor, moradores de bairros próximos, além disso, tornou-se um campo de estudo para pesquisadores de várias instituições de ensino. A feira da SAF é frequentada pelos funcionários da secretaria; os demais mercados abrangem os moradores do bairro onde está localizada.

O projeto que envolve a Feirinha da Agronomia e Feirinha da SAF se diferenciam das demais em decorrência das suas regra de participação, permitindo somente a venda de produtos locais, o que reforça a busca pela alternatividade nos critérios dos CCAAs.

\footnotetext{
${ }^{10}$ Apesar de distinguirmos os canais de comercialização de forma simplista, principalmente em relação ao que denominamos como alternativo e convencional, esta escolha metodológica nos permitiu analisar as experiências encontradas em campo juntamente com as abordagens teóricas privilegiadas na pesquisa.
} 
Segundo entrevista com a coordenadora da feirinha da agronomia e também professora do curso de Agronomia (UEMA), quando os consumidores realizam a compra dos produtos diretamente dos agricultores, o que está envolvido não é somente uma troca econômica, pois a feira oferece aos agricultores um espaço de interação com a universidade e com os consumidores, tornando-se, ao mesmo tempo, um espaço de resistência ao sistema alimentar convencional (GOODMAN, 2017). Com isso, existe uma troca de saberes entre estudantes, professores, moradores locais e agricultores periurbanos.

Para os entrevistados, quando comparado o interesse dos consumidores da feira da agronomia com os da Feira Nova República, caracterizada pela presença massiva de feirantes comerciantes, tem-se na primeira um consumidor mais ativo e participativo, enquanto que na segunda, não demonstram interesse pela origem dos alimentos ou processo de produção. Chamamos atenção para o protagonismo do consumidor nos mercados mais alternativos, pois não se trata somente da forma de comercialização, ou seja, a venda direta, haja vista que são realizadas em ambos os mercados, mas das motivações que direcionam os consumidores a comprar diretamente de agricultores familiares. Como apresentam Renting, Marsden e Banks (2017), uma das características das CCAA é sua capacidade de ressocializar ou reespacializar o alimento, permitindo que o consumidor possa fazer julgamentos de valor.

\subsection{Relações com Intermediários}

Nas feiras alternativas e convencionais, a figura do intermediário aparece em três momentos: quando os atravessadores compram diretamente dos produtores; quando os agricultores compram de atravessadores para comercialização em algumas dessas feiras; e no momento que o agricultor assume o papel de atravessador.

O primeiro caso é representado pela venda no Mercado do João Paulo que, como centro atacadista, é vendido a feirantes comerciantes ou atravessadores; e a venda de frango caipira na comunidade, com destino a restaurantes ou boxes de frango nas feiras da cidade. Nos dois casos percebemos que não se formam laços sociais com pessoas específicas devido a variação constante de atravessadores com os quais fazem negócio, no entanto, na venda de frangos, semelhante ao estudo de Craviotti (2017), o papel do intermediário torna-se positivo por oferecerem melhores remunerações e maior volume comercializado em comparação as feiras, bem como, por reduzir os custos de transporte, haja vista que a compra é realizada diretamente na comunidade.

Em segundo lugar, a intermediação ocorre quando são incorporados a venda nas feiras, produtos exógenos, a fim de complementar a cesta de alimentos e atender a algumas exigências dos consumidores, acontecendo com mais frequência nos mercados convencionais em cadeias curtas, porém, essa relação também é encontrada nos mercados alternativos, embora com produtos em menor volume, já que predomina a venda de alimentos locais. Nas feiras da SAF e da Agronomia, os produtos comprados nas centrais de abastecimento são fornecidos por alguns agricultores com pedidos prévios do consumidor, evitando-se a exposição desses alimentos nas bancas, por ser proibido segundo as regras. 
Quando questionados a respeito da importância de comercializar nas feiras livres somente o que é produzido localmente, as respostas seguem duas linhas de pensamento, os que são contra a venda de produtos de fora e os que são a favor, conforme vemos nos discursos a seguir:

Eu acho que não é bom não, muitos faz isso, mas eu não faço não. Tu sabe por quê? Porque não me dá lucro, eu gosto de trabalhar, mas quero saber o que tô fazendo. A feira nunca garante que você vende seus produtos todos. (...) Na feirinha da agronomia tem o estatuto que não deixa vender esses produtos, mas mesmo assim tem é muita gente que vende (AGRICULTOR 1 , FEIRA DA AGRONOMIA, 2018).

Quando eu não tenho produto eu compro de outro colega produtor que tem, não gosto de tá comprando no mercado, porque eu me preocupo muito com a qualidade do produto. $O$ consumidor sabe o que é produzido aqui e o que é lá do Ceará, Bahia. Quando não tem produto aqui, compramos de colegas de outros municípios do Maranhão, pra não comprar de outro estado (AGRICULTOR 2, FEIRA DA AGRONOMIA, 2018).

\begin{abstract}
Eu acho que é válido terminar de interar, porque se tu chega na minha mesa tu vai comprar uma coisa, tu só tem cheiro verde, aí tu vai numa mesa que tem tomate, cheiro verde, cebola, batata, que tem tudo... tu vai comprar tudo, tu vai deixar só o cheiro verde pra comprar na minha mão? Logicamente que não! Quer dizer então que eu vou perder cliente! Eu tenho que ter na minha banca o que o cliente pede. Na Feira da SAF é diferente, porque eles já sabem o que eu levo. Eles me procuram por tomate, cebola, mas eU DIGO QUE SÓ VOU BOTAR SE A DIREÇÃO AUTORIZAR (AGRICULTOR 3, FEIRA DA SAF, 2018).
\end{abstract}

Nesses relatos, identificamos os cálculos que são feitos no momento da comercialização, apesar de um dos agricultores apontar para sua preocupação com a valorização dos produtos locais, o que percebemos nas outras duas entrevistas é que suas decisões são pautadas primeiramente na busca por melhores rendimentos, recaindo sobre uma das críticas apresentadas por Tregear (2011) às RAAs, com análises de experiências que trazem consigo uma visão ideologizada do alternativo. Como pudemos perceber, a alternatividade dos CCAA apresenta seus limites, quando vemos uma justaposição com as redes convencionais (FONTE, 2010; CASSOL; SCHNEIDER, 2017) ao optarem por comprar produtos exógenos para serem vendidos na feira do produtor.

No segundo momento, verificamos o próprio agricultor como atravessador, haja vista que, em razão da demanda por uma produção diversificada, os próprios agricultores atuam como intermediários comprando alimentos dentro da comunidade para levarem as feiras livres e/ou fornecerem aos mercados institucionais. Geralmente o mesmo agricultor que compra também vende alimentos aos agricultores locais, seja do Cinturão Verde ou de outras comunidades próximas. Também existem aqueles que compram para vender nos Centros Atacadistas como o mercado do João Paulo, tornando a cadeia mais longa.

Apesar de haver algumas discordâncias quanto ao número de atravessadores que caracterizem cadeias curtas, o mesmo não ocorre quanto a ênfase no relacionamento entre produtores e consumidores neste tipo de cadeia para serem 
consideradas nos termos de alternativo. Desta forma, quando a venda é realizada para outros agricultores familiares comercializarem em feiras livres ou mercados institucionais, ainda se mantem a garantia da autenticidade dos produtos, comunicando sua origem ao consumidor, enquanto que aquele produtor que compra para revender no mercado do João Paulo o faz sem qualquer informação do destino final do produto. Neste sentido, em uma primeira observação, se delineia um limite claro entre os dois tipos de intermediação realizados por agricultores do Cinturão Verde, ou seja, aquele que se mantém em um sistema mais alternativo e uma cadeia mais curta, e outro que privilegia o mais convencional numa cadeia mais longa, no entanto, verificamos nas entrevistas apresentadas que os mesmos agricultores que acessam as cadeias curtas, também o fazem nas cadeias longas.

\subsection{Definições dos preços}

Um aspecto importante identificado com frequência nas falas dos entrevistados refere-se à formação de preços nas feiras e mercados. De modo geral, os preços são definidos fundamentados no mercado convencional. Na feirinha da agronomia, os produtores têm como base os preços encontrados no supermercado da maior rede do estado, a qual tem uma loja localizada a $2,5 \mathrm{~km}$ da UEMA, a partir disso, segundo um dos entrevistados, eles estabelecem, em uma decisão conjunta, preços menores sem haver prejuízos ao produtor.

Constatamos em entrevista com a coordenadora da Feirinha da Agronomia que o estabelecimento do preço é uma das tentativas de diferenciar-se do mercado convencional. Neste sentido, sinalizamos que preços mais baixos ao consumidor na Feirinha da agronomia é resultado de venda dos produtos locais, enquanto que preços maiores indicava a comercialização de produtos comprados em centros atacadistas.

Conforme explica Belletti e Marescotti (2017), o que está em jogo nas CCAAs não é uma lógica de preços "altos" (para produtores) ou preços "baixos" (para consumidores), mas a busca por preços "certos" e "justos", equilibrando as necessidades dos produtores e consumidores. Desta forma, a coordenação da feirinha da agronomia atua como reguladora na definição de preços, incentivando a diversificação da produção, agregação de valor ao produto no lugar de incorporar produtos não locais. Apesar disso, sinalizamos que ainda existe um projeto de alternatividade limitado do produtor - o que acarretou na saída de alguns agricultores no início da feira. Embora tenha sido notado a escolha dos consumidores por produtos da agricultura familiar, segundo a coordenadora e os agricultores entrevistados, ainda existe uma procura muito pautada nos preços praticados nesta feira, o que pode indicar um projeto de alternatividade ligado ao consumidor ainda pouco expressivo nos padrões dos CCAAs. Quanto às demais feiras livres, como a feira da SAF, Feira Livre da Vila Sarney, Feira São Luís Rural, Feira da Nova República e Feira da Agerp, os preços são definidos com base no mercado do João Paulo, não havendo controle dos preços por instituições fiscalizadoras. Sendo assim, a regulação é de responsabilidade dos próprios agricultores. Como explicaram: "todos acompanham os mesmos preços, assim não tem conflito"; "me baseio no preço que os outros feirantes estão vendendo"; 
"coloco de acordo com o do vizinho, pela experiência eles já sabem a faixa de preços" (Informação verbal).

Quanto ao mercado convencional em circuito longo, temos como representante o mercado do João Paulo. Quando perguntamos a respeito das vantagens e desvantagens da comercialização nesse mercado, as respostas foram muito semelhantes. A principal vantagem está relacionada com o volume vendido e a desvantagem são os baixos preços praticados, acarretando em uma forte dependência ao estabelecido pelos atravessadores. Por outro lado, há o risco de não vender tudo e retornar com o alimento para casa, conforme o relato de um dos entrevistados ao falar da venda da macaxeira (Manihot esculenta Crantz), comparando os preços praticados nos mercados institucionais, feiras livres e mercado do João Paulo:

\footnotetext{
Eu tô tirando uma média agora de 5 caixa por semana, é um programa que tem aí, da SAF, o PROCAF. Eu entrego toda semana cinco caixas, dá uma média de $R \$ 75,00$ a caixa. Se eu vendo na feira da UEMA, é $R \$ 2,500$ $\mathrm{kg}$, deve dá uns $\mathrm{R} \$ 65,00$. No João Paulo eles não querem dar mais do que $\mathrm{R}$ 25,00 numa caixa, aí eu nem levo. Um dia desses nós tinha muita, e ainda não tinha chegado o programa, peguei 12 caixas e levei pra Feira do João Paulo, dia de sábado, aí eu cheguei lá e vendi seis caixas. Eu vendi duas caixas por $\mathrm{R} \$ 40,00$, deu $\mathrm{R} \$ 20,00$ cada uma. Eu fiquei lá, aí quando amanheceu o dia, chegou um cara dizendo "rapaz, quer vender isso aí? Quanto é? Eu quero quatro caixas. Eu respondi “é $\mathrm{R} \$ 25,00$ ” cada. Ele falou que não queria. Aí eu disse que deixava por $\mathrm{R} \$ 15,00$, ele disse "Tu quer $\mathrm{R} \$ 50,00$ em quatro caixas? E eu respondi que podia ser. O que eu apurei no fim foi $\mathrm{R} \$ 90,00$, e ainda voltei pra casa com seis caixas (AGRICULTOR 4, MERCADO DO JOÃO PAULO, 2018).
}

Neste caso, salientamos que a dependência estrita de um mercado convencional acarretaria em baixo nível do preço em relação aos custos e, consequentemente, na retirada deste agricultor do setor. Apesar de apresentarem a "vantagem" de maiores volumes comercializados, este mercado é procurado quando as feiras e demais circuitos acessados não são suficientes para absorver a produção. Assim, as debilidades do mercado convencional se apresentam na forma de baixa remuneração ao produtor, levando a concorrer com produtos vindos de outros estados, geralmente com preços baixos, e concorrendo entre si, já que é um espaço de comercialização de agricultores da ilha de São Luís. Além do mais, o agricultor não tem autonomia para definir seu preço, ficando completamente dependente do atravessador, com o argumento de que é "melhor vender a preços baixos do que dar pros porcos" (INFORMAÇÃO VERBAL).

Vemos, então, a diferença de preços entre os mercados institucionais, feira livre e Mercado do João Paulo, demonstrando que a ausência das feiras e dos programas de compras públicas colocaria os produtores em uma situação de completa insegurança e dependência na hora de comercializar seus produtos.

Quando perguntados sobre qual dos mercados acessados tem os melhores preços, eles afirmaram serem os mercados institucionais (PAA, PNAE e PROCAF) e isso ocorre, também, pelo maior volume de venda. Alguns agricultores declararam que, mesmo com alguns valores defasados, ainda são mais vantajosos ao produtor e o preço de um produto é compensado em outro. Para o enquadramento desses 
programas nos critérios que compõe uma CCAA, Morgan e Sonnino (2008) defendem que os princípios para compras públicas devem pautar-se na qualidade do alimento adquirido e seus benefícios para a sociedade, a saúde, e ambiente no médio e longo prazo, não na busca exclusivamente do menor preço, no entanto, os avanços neste sentido ainda perfazem iniciativas isoladas, em nível micro.

\title{
4.4 Exigências de qualidade
}

As exigências por qualidade foram citadas pelos agricultores entrevistados a partir da ótica de valorização da produção de base familiar, a qual coloca valor ao produto quando comercializado nas feiras livre, considerando o lugar de produção, pouco uso de agrotóxicos, respeitando o ambiente, segundo alguns dos critérios apresentados por Renting, Marsden e Banks (2017).

Nos circuitos convencionais, a qualidade é apresentada quando o consumidor que compra dos intermediários, passa a exigir produtos mais frescos, à exemplo do depoimento a seguir:

\begin{abstract}
Algumas coisas a gente concorre, o cheiro verde, por exemplo, teve uns dois anos atrás que a gente levava nosso cheiro daqui e voltava com ele, porque o Ceará tinha dominado, nem era por causa do preço, era porque o cheiro deles era mais bonito, mas ele tinha tanta coisa química que ele saia do Ceará e chegava mais verde que o nosso que era plantado aqui. $\mathrm{E}$ eu acho que o pessoal foram caindo na real, por que o cheiro deles não pode pegar água, ele desmancha todinho. E o cheiro de lá tá ficando barato porque o pessoal tá deixando de amarrar, e eu já levo amarradinho com a cebolinha, a salsinha e o coentro tapuio (AGRICULTOR 5, MERCADO DO JOÃO PAULO, 2018).
\end{abstract}

À vista disso, a escolha do consumidor se pautou nos aspectos físicos do produto, provavelmente sem saber a origem do alimento de melhor "qualidade" escolhido. Os agricultores, por sua vez, se vêem em um contexto de adaptação constante para se manterem produzindo e comercializando. Assim, o método de apresentação do cheiro verde para comercialização possibilitou fazer frente a alguns produtos exógenos, demonstrando uma possível vinculação da agricultura periurbana à economia de mercado, e uma luta constante para se adequarem em um ambiente de concorrência desigual.

Nos Mercados Institucionais, a questão da qualidade dos alimentos perpassa pelos agentes recebedores - Conselho de Alimentação Escolar (CAE), a merendeira, a direção da escola, os professores e todos que fazem parte da comunidade escolar - que a partir de critérios estritamente sanitários e de segurança dos alimentos, atestam sua qualidade.

Em resumo, dentre as categorias apresentadas por Renting, Marsden e Banks (2017), a que se mostrou mais significativa no discurso dos agricultores entrevistados quanto a comercialização nos circuitos mais alternativos, está relacionada qualidade atribuída ao produto e ao lugar de produção, bem como a bioprocessos, sobretudo com produtos com baixo uso de agroquímicos. Em contrapartida, nos demais mercados, convencionais e institucionais, o que predomina são as características físicas e sanitárias dos produtos. 


\section{Conclusão}

Neste artigo, procuramos discutir acerca da dicotomia alternativo versus convencional, a partir do acesso a diferentes circuitos de comercialização pelos agricultores periurbanos do Cinturão Verde, considerando as dimensões da alternatividade presentes nos CCAAs.

Portanto, foram identificados em dois mercados alternativos (feirinha da Agronomia e feirinha da SAF) a ocorrência dos princípios da chamada "alternatividade", tal como é discutida nos estudos das RAAs. Ao direcionar o olhar às quatro dimensões discutidas, presenciamos uma tentativa de se diferenciar dos mercados convencionais principalmente no que tange a valorização da produção local, presença de consum'atores, preços justos, redução de intermediários, e qualidade atrelada a multifuncionalidade da agricultura familiar e pouco uso de agroquímicos na produção. Para isso, foram criadas regras de participação a fim de resguardar os princípios que regem as feiras livres. No entanto, ainda existem mecanismos de difícil controle nesses espaços como a formação de preços ainda muito relacionada ao praticado nos supermercados, bem como, a manutenção de produtos estritamente da agricultura familiar, este último, presenciado mais fortemente nas demais feiras livres em cadeias curtas, que são mais flexíveis quantos as regras estabelecidas (Feira São Luís Rural do Angelim; Feira livre da Vila Sarney; Feira da Agricultura Familiar da AGERP).

Identificamos um processo de atravessamento entre os agricultores familiares para abastecimento das feiras livres e mercados institucionais. Neste caso, embora não se presencie a venda direta, os produtos se diferenciam quanto à trajetória que percorrem entre os produtores e consumidores, mantendo o princípio de comercialização de produtos locais, comunicando sua origem. Ao mesmo tempo, também verificamos uma relação positiva com atravessadores que compram frango na comunidade, relatada através dos preços justos praticados e redução de custos com transporte. Em contrapartida, no caso da venda em circuito longo no Mercado do João Paulo, há uma relação de exploração pelos intermediários, principalmente em termos de preços praticados, reforçando a lógica de atuação das cadeias de abastecimento convencionais em um contexto altamente competitivo e regulatório, desvantajoso ao agricultor.

Com isso, verificamos que os agricultores pesquisados acessavam os mercados convencionais tanto em cadeias curtas quanto cadeias longas, demonstrando a busca por melhores rendimentos, o que foge a visão encantada das feiras livres como espaços onde a prioridade são as relações sociais de confiança entre consumidor e produtor. Ao contrário, o objetivo principal perpassa pela busca por autonomia e reprodução social da unidade familiar, como observamos nas vendas no Mercado do João Paulo, pois, embora seja citado como aquele cujos preços são os mais baixos em relação aos demais (feiras e mercados institucionais), não deixou de ser acionado por nenhum dos agricultores entrevistados. Além disso, a dicotomia entre ambos sistemas de comercialização não se mostrou efetivo, quando mesmo nas feiras livres verificava-se mecanismos próprios das cadeias de abastecimento convencional, principalmente quanto a definição de preços e venda de produtos não locais. 
Relativamente à alternatividade das feiras investigadas, verificamos que, como aponta Tregear (2011), apesar de redes alimentares alternativas serem movidas pelo ideal de um engajamento de produtores e consumidores que priorizem objetivos de justiça social, igualdade e sustentabilidade, nos casos discutidos, presenciamos redes "imperfeitas", onde os agricultores que se envolvem em venda direta não necessariamente o fazem por razões altruístas de sustentabilidade, demonstrado através de seu engajamento em outras atividades pré-existentes, inclusive outras cadeias de comercialização que fogem ao principio do que seria "alternativo".

\section{REFERÊNCIAS}

ALLEN, P.; FITZ SIMMONS, M.; GOODMAN, M.; WARNER, K. Shifting places in the agrifood landscape: the tectonics of alternative agrifood initiatives in California. Journal of Rural Studies, 19, p. 61-75, 2003.

AUBRI, C.; CHIFFOLEAU, Y. Le développement des circuits courts et l'agriculture périurbaine: histoire, évolution en cours et questions actuelles. Innovations Agronomiques, v. 5, p. 53-97, 2009. Disponível em: https: //www6.inra.fr/ciag/content/download/3324/34568/file/Ciag5-6-Aubry.pdf. Acesso em: 27 jan. 2018.

BELLETTI, G.; MARESCOTTI, A. Inovações econômicas em cadeias curtas de abastecimento alimentar. In: SCHNEIDER, S. GAZOLLA, M. (Orgs.). Cadeias curtas e redes agroalimentares alternativas: negócios e mercados da agricultura familiar. Porto Alegre: Editora da UFRGS, 2017, p. 129-145.

BLAY-PALMER, A., RENTING, H.; DUBBELING, M. City-region food systems: a literature review. Leusden: RUAF Foundation, 2015. Disponível em: $<$ https:<//ruaf.org/assets/2019/12/City-Region-Food-Systems-literature-review.pdf >. Acesso em: 12 mar. 2020.

BRAGA, C. L. Circuitos de comercialização, mercados e estratégias de reprodução dos agricultores periurbanos da comunidade rural Cinturão Verde em São Luís (MA). Dissertação (Mestrado em Ciências Sociais), Universidade Federal do Maranhão, São Luís, 2019.

BRAGA, C. L.; CARNEIRO, M. S. Transformações na agricultura periurbana da MRH da aglomeração urbana de São Luís. RAIZES (UFPB), v. 39, p. 241-261, 2019.

BRUNORI, G.; GALLI, F. Sustainability of Local and Global Food Chains: Introduction to the Special Issue. Sustainability, v. 8, p. 1- 7, 2016.

CASSOL, A.; SCHNEIDER, S. Construindo a confiança nas cadeias curtas: interações sociais, valores e qualidade na Feira do Pequeno Produtor de Passo Fundo/RS. In: SCHNEIDER, S. GAZOLLA, M. (Orgs.). Cadeias curtas e redes agroalimentares 
alternativas: negócios e mercados da agricultura familiar. Porto Alegre: Editora da UFRGS, 2017, p. 195-217.

CORDEIRO, E. F. Sistemas Alimentares Alternativos: o papel dos circuitos curtos de comercialização de produtos agroecológicos em Florianópolis, SC. Florianópolis, 2014, 216f. Dissertação (Mestrado em Agroecossistemas), Universidade Federal de Santa Catarina, Santa Catarina, 2014.

CRAVIOTTI, C. La problemática de la coexistencia entre la agricultura familiar y la agroindustria: una aproximación desde la producción de quesos. Revista Brasileira de Sociologia, V. 5, n. 10, Mai-Ago, 2017. Disponível em: http://www.sbsociologia.com.br/revista/index.php/RBS/article/download/209/149. Acesso em: 15 fev. 2018.

DAROLT, M. R.; LAMINE, C.; BRANDENBURG, A.; ALENCAR, M. De C. F.; ABREU; L. S. Redes alimentares alternativas e novas relações produção-consumo na França e no Brasil. Ambiente \& Sociedade. São Paulo v. XIX, n. 2, p. 1-22, abr.-jun. 2016.

Disponível em: http://www.redalyc.org/html/317/31746369002/. Acesso em: 5 jan. 2018.

DILL, M. D.; CORTE, V. F. D.; OLIVEIRA, C. A. O. de; BARCELLOS, J. O. J.; CANOZZI, M. E. A.; GIANEZINI, M. Venda Direta: o principal canal de comercialização de carne bovina e suína das agroindústrias rurais do Brasil. Agronegócios e Meio Ambiente, v.7, n. 2, p. 337-357, 2014.

FONTE, M. Food relocalisation and knowledge: dynamics for sustainability in rural areas. In: FONTE, M.; PAPADOPOULOS, A. G. (Ed.). Naming food after places: food relocalisation and knowledge dynamics in rural development. Farnham: Ashgate, 2010, p. 1-35.

GOMES, J. F. B. A multifuncionalidade da Agricultura Urbana e a sua integração no ecossistema urbano da ilha de São Luís. Dissertação (Mestrado em Desenvolvimento Socioespacial e Regional), Universidade Estadual do Maranhão, São Luís, 2016.

GOODMAN, D. Agro-food studies in the age of ecology: nature, corporeality, bio-politics. Sociologia Ruralis, v. 39, p.17-38, 1999.

GOODMAN, D. Espaço e lugar nas redes alimentares alternativas: conectando produção e consumo. In: SCHNEIDER, S.; GAZOLLA, M. (Orgs.). Cadeias curtas e redes agroalimentares alternativas: negócios e mercados da agricultura familiar. Porto Alegre: Editora da UFRGS, 2017, p.259-280.

GRANOVETTER, M. Ação econômica e estrutura social: o problema da imersão. RAE electron., São Paulo, v. 6, n. 1, 2007. 
GUTHMAN, J. Commodifield Meanings, Meaningful, Commodities: Re-thinking Production-Consumption Links through the Organic System of Provision. Sociologia Ruralis, vol. 42, n 4, p. 295-311, 2002.

LE VELLY, R. Sociologie des Systèmes Alimentaires Alternatifs. Une promesse de différence. Paris: Presses des Mines, 2017.

MARSDEN, T. K. New rural territories: regulating the differentiated rural spaces. Journal of Rural Studies, v. 14, n.1, p. 107-117, 1998.

MARSDEN, T.; BANKS, J.; BRISTOW, G. Food supply chain approaches: exploring their role in rural development. Sociologia Ruralis, vol. 40, n. 4, p. 424-438, 2000. Disponível em: http://onlinelibrary.wiley.com/doi/10.1111/1467-9523.00158/pdf. Acesso em: 2 fev. de 2018.

MARSDEN, T.; RENTING, H. Compreendendo as Redes Alimentares Alternativas: o papel de cadeias curtas de abastecimento de alimentos no desenvolvimento rural. In: SCHNEIDER, S. GAZOLLA, M. (Orgs.). Cadeias curtas e redes agroalimentares alternativas: negócios e mercados da agricultura familiar. Porto Alegre: Editora da UFRGS, 2017, p. 53-58.

MORGAN, K.; SONNINO, R. The School food revolution: public food and the challenge of sustainable development. London: Earthscan, 2008.

MURDOCH, J.; MARSDEN, T. K.; BANKS, J. Quality, nature, and embeddedness: some theoretical considerations in the context of the food sector. Economic Geography, v. 76, n. 2, p. 107-125, 2000.

NIEDERLE, P.A. ; ALMEIDA, L. A nova arquitetura dos mercados para produtos orgânicos: o debate da convencionalização. In: NIEDERLE, P.; ALMEIDA, L.; VEZZANI, F. (Orgs.) Agroecologia: práticas, mercados e políticas para uma nova agricultura. 1ed. Curitiba: Kayrós, UFPR, 2013.

PLOEG, J. van der; RENTING, H.; BRUNORI, G.; KNICKEL, K.; MANNION, J.; MARSDEN, T.; DE ROEST, K.; SEVILLA-GUZMAN, E.; VENTURA, F. Rural Development: From Practices and Policies towards Theory. Sociologia Ruralis , v. 40, n. 4, p. 391-408, 2000.

POLANYI, K. A grande transformação: as origens de nossa época. Tradução de Fanny Wrabel. 2. ed. Rio de Janeiro: Compus, 2000.

POMÉON, T.; FOUILLEUX, E.; LEMEILLEUR; S.; LOCONTO, A. L'agriculture biologique en France, entre projet critique et conventionnalisation. In: ALLAIRE, G., DAVIRON, B. (Orgs.). Transformations agricoles et agroalimentaires: entre écologie et capitalisme. Versailles: Éditions Quæ, 2017. 
PREISS, P. V.; MARQUES, F. C. Tendências no movimento de re-localização alimentar brasileiro: uma análise de Iniciativas Colaborativas de Compras. Tessituras, Pelotas, v. 3, n. 2, p. 269-300, jul./dez, 2015.

RENTING, H.; MARSDEN, T.; BANKS, J.. Compreendendo as redes alimentares alternativas: o papel de cadeias curtas de abastecimento de alimentos no desenvolvimento rural. In: SCHNEIDER, S. GAZOLLA, M. (Orgs.). Cadeias curtas e redes agroalimentares alternativas: negócios e mercados da agricultura familiar. Porto Alegre: Editora da UFRGS, 2017, p. 27-51.

SABOURIN, E. Comercialização dos produtos agrícolas e reciprocidade no Brasil. Estudos, Sociedade e Agricultura, Rio de Janeiro, vol. 21, n. 1, p. 5-33, 2013. Disponível em: https://agritrop.cirad.fr/571026/1/document_571026.pdf. Acesso em: 26 fev. 2018.

SAGE, C. The interconnected challenges for food security from a food regimes perspective: energy, climate and mal consumption. Journal of Rural Studies, 29, p. 71- 80, 2013.

SCHNEIDER, S.; GAZOLLA, M. Cadeias curtas e redes agroalimentares alternativas. In: SCHNEIDER, S. GAZOLLA, M. (Orgs.). Cadeias curtas e redes agroalimentares alternativas: negócios e mercados da agricultura familiar. Porto Alegre: Editora da UFRGS, 2017, p. 9-24.

SONNINO, R.; MARSDEN, T. Além da linha divisória: repensando relações entre redes alimentares alternativas e convencionais na Europa. In: SCHNEIDER, S.; GAZOLLA, M. (Orgs.). Cadeias curtas e redes agroalimentares alternativas: negócios e mercados da agricultura familiar. Porto Alegre: Editora da UFRGS, 2017, p. $105-127$.

STEINER, P. A sociologia econômica. Tradução de Maria Helena C. V. Trilinski. São Paulo: Atlas, 2006.

TREGEAR, A. Progressing knowledge in alternative and local food networks: critical reflections and a research agenda. Journal of Rural Studies, Oxford, v. 27, n. 4, p. 419-430, Oct. 2011.

TRICHES, R. M. Repensando o mercado da alimentação escolar: novas institucionalidades para o desenvolvimento rural. In: GRISA, C.; SCHNEIDER, S. (Orgs.) Políticas Públicas de desenvolvimento rural no Brasil. Porto Alegre: Editora da UFRGS, 2017, p. 181-200.

WILKINSON, J. Mercados, redes e valores: o novo mundo da agricultura familiar. Porto Alegre: Editora da UFRGS, 2008. 
Marcelo Sampaio Carneiro. Doutor em Sociologia (PPGSA/UFRJ). Professor do Departamento de Sociologia e Antropologia da Universidade Federal do Maranhão (UFMA). Campus São Luís - MA. mdscarneiro@uol.com.br

Camila Lago Braga. Socióloga e Engenheira Agrônoma. Doutoranda em Desenvolvimento Rural (PGDR/UFRGS). Porto Alegre - RS. camila.lago.braga@gmail.com.

Como citar: CARNEIRO, Marcelo Sampaio; BRAGA, Camila Lago. Alternativo versus convencional: uma análise da inserção de agricultores familiares periurbanos em circuitos de comercialização no município de São Luís/MA. Redes (St. Cruz Sul, Online), Santa Cruz do Sul, v. 25, n. 2, p. 545-569, maio 2020. ISSN 1982-6745. Disponível em: https://online.unisc.br/seer/index.php/redes/article/view/14857 Acesso em: 22 maio 2020. doi: https://doi.org/10.17058/redes.v25i2.14857

\section{CONTRIBUIÇÕES NA ELABORAÇÃO DO ARTIGO}

A) Fundamentação teórico-metodológica e problematização: Camila Lago Braga e Marcelo Sampaio Carneiro

B) Pesquisa de dados e análise estatística: Camila Lago Braga

C) Elaboração e redação do texto: Camila Lago Braga e Marcelo Sampaio Carneiro

D) Seleção das referências bibliográficas: Camila Lago Braga e Marcelo Sampaio

Carneiro 